\title{
Regulation of Fetal Lung Phosphatidyl Choline Synthesis by Cortisol: Role of Glycogen and Glucose
}

\author{
( ARL GILDEN, ALIX SEVANIAN, DONALD F. TIIERNIEY, SOLOMON A. KAPLAN, AND \\ (YNTHA T. BARRIOTTT+1" \\ Deparments of Pediatrics and Medicine, UCLA School of Medicine, Los Angeles. California, USA
}

\begin{abstract}
Summary
Twenty pregnant rabbits were studied in pairs. Half were given cortisol subcutancously on days 24,25 , and 26 of gestation in dosage of $2 \mathrm{mg} / \mathrm{kg} / \mathrm{day}$. Half served as controls and received saline. The fetal lungs were studied on the $27 \mathrm{th}$ day of gestation by incubating lung slices in the presence of $\left[6-{ }^{11} \mathrm{C}\right]$ glucose. Glucose consumption significantly increased in the tissues from animals treated with cortisol, $17.61 \pm 5.56$ (SD) $\mu \mathrm{mol} / \mathrm{g}$ wet lung versus $14.28 \pm 5.78$ (SD) $\mu \mathrm{mol} / \mathrm{g}$ in the controls $(P<$ $0.05)$. The glycogen content of tissues treated with cortisol was significantly reduced compared to the controls, $2.42 \pm 0.97$ (SD) $\mathrm{mg} / \mathrm{g}$ wet lung versus $3.81 \pm 1.05$ (SD) $\mathrm{mg} / \mathrm{g}(P<0.05)$. Ireatment with cortisol resulted in significantly enhanced incorporation of the ${ }^{14} \mathrm{C}$ label into glycogen and phosphatidyl choline (Tables 3 and 4). These data suggest that glucocorticoids affect fetal lung phosphatidyl choline production by promoting glycogenolysis and increasing glucose incorporation into phosphatidyl choline.
\end{abstract}

\section{Speculation}

Diminished glycogen content of the fetal lung in the latter part of gestation may reflect increasing utilization for phosphatidyl choline synthesis. Adenosine $3^{\prime},-5^{\prime}$-monophosphate (cyclic AMP) increases which occur after glucocorticoid administration may be responsible for activation of glycogen phosphorylases in the lung as they are in the liver. If insulin inhibits glycogenolysis in the lung as it does in the liver, insulin may inhibit phosphatidyl choline synthesis in the lung by preventing glycogen and glucose from serving as precursors.

Glucocorticoid administration to pregnant sheep. rabbits. monkeys. and human beings can induce premature maturation of the pulmonary surfactant system in the fetus $(6,15.17 .19$. 20. 24. 35). The mechanism by which these agents induce premature maturation of fetal lungs is not clear. Farrell and Zachman (7. 8) have shown that antenatal administration of glucocorticoids to fetal rabbits results in increased activity of choline phosphotransferase. a rate-limiting enzyme for phosphatidyl choline synthesis through the choline incorporation pathway described by Kennedy (14). We have reported that in fetal rabbit lung. cortisol inhibits cyclic AMP phosphodiesterase. increases concentrations of cyclic $A M P$. and increases incorporation of choline and methionine into phosphatidyl choline (1). Glucocorticoids have multiple effects on carbohydrate metabolism through the de nove synthesis of a number of enzymes of the glycolytic pathway. including fructose-1.6-diphosphatase (23). phosphohexose isomerase (38), glueose-(6-phosphatase (37), and phosphoenolpyruvate carboxykinase (29). In tissues such as liver and muscle, the glycolytic pathway is closely coupled to the pathways involved in phospholipid synthesis (5). The widespread metabolic effects of glucocorticoids may also influence the availability and utilization of substrates for phosphatidyl choline synthesis.

Glucose has been shown to be an important precursor for phosphatidyl choline synthesis in adult rabbit lung (9), and there is indirect evidence that glycogen is a precursor for phosphatidyl choline in fetal rabbit lung $(15,24,35)$. Between 25 and 28 days of gestation, the amount of glyeogen, which had previously been high, decreases and disappears from the alveolar type II cells (15). Simultaneously, lamellar inclusion bodies, the storage sites for surfactant (16), appear in greater numbers and it has been suggested that this observation implies that glycogen may be a precursor for surfactant (15). Glucocorticoids also affect lipid metabolism, promoting lipolysis in adipose tissue with the release of glycerol and free fatty acids (25), both of which are precursors for phosphatidyl choline synthesis $(22,32,33)$. It appears, therefore, that glucocorticoids have multiple effects upon pulmonary metabolism, which may result in increased phosphatidyl choline synthesis. The present study was undertaken to determine whether glucocorticoids affect fetal lung phosphatidyl choline production by modifying glucose utilization or conversion.

\section{MATERIALS AND METHODS}

Twenty pregnant New Zealand albino rabbits, conception timed to within $3 \mathrm{hr}$, were studied in pairs. Half were given cortisol (hydrocortisone phosphate) subcutaneously, $2 \mathrm{mg} / \mathrm{kg} /$ day in three equal doses on days 24, 25, and 26 of gestation. Half served as controls, received saline subcutaneously, but were otherwise treated identically.

On the 27th day of gestation the fetuses were delivered by cesarean section immediately after killing the doe with intravenous pentobarbital followed by $\mathrm{KCl}$. The tracheas of the fetuses were clamped immediately after delivery and the spinal cord was severed. This prevented air breathing and loss of tracheal fluid. The lungs were excised and placed in cold Krebs-Ringer bicarbonate buffer, as modified by $\mathrm{O}^{\prime}$ Neil and Tierney (26). The lungs were rinsed in the same buffer and blotted with a dry gauze sponge. Tissue slices of $\mathrm{i} 000 \mathrm{~mm}$ were then prepared using a Mellwain tissue slicer as described by $O$ Neil and Tierney (26). Approximately $300 \mathrm{mg}$ tisste were added to $4.5 \mathrm{ml}$ KrebsRinger buffer, pH 7.4 , containing $0.563 \mathrm{mCi}\left[6-^{1.4} \mathrm{C}\right]$ glucose ( $4.87 \mathrm{mCi} / \mathrm{mmol}$, New England Nuclear Corp.) in incubation flasks with center wells. The flasks were weighed before and after the addition of tissue and the amount of tissue added to each flask was thus determined. After equilibration for $45 \mathrm{sec}$ with $95 \%$ ( $\%_{2}$ and $5 \% \mathrm{CO}_{2}$, the flasks were capped and incubated for $90 \mathrm{~min}$ in a Dubnoff metabolic shaker set at $38^{\circ}$ and 120 oscillations/min. After the incubation, the flasks were placed on 
ice. To some flasks in each group $0.5 \mathrm{ml}$ quarternary amine (NCS, New England Nuclear Corp.) was placed into the center well and $2 \mathrm{ml} 6 \%$ perchloric acid were placed in the outer compartment by means of a needle while the flasks remained sealed. These flasks were incubated again for $60 \mathrm{~min}$ to collect $\mathrm{CO}_{2}$ in the quarternary amine. The quarternary amine containing ${ }^{14} \mathrm{CO}_{2}$ was transfered to vials to which an Aquasol-ethanol (New England Nuclear Corp.) based solution was added, and counted in a liquid scintillation counter (Nuclear Chicago Isocap 300 ). Glucose oxidation was calculated by multiplying the ratio of disintegrations per min of ${ }^{14} \mathrm{CO}_{2}$ to disintegrations per min of $\left[6-{ }^{4} \mathrm{C}\right]$ glucose originally added to the flask, by the amount of glucose initially present in the medium.

Tissue glyeogen content was determined before and after incubation by the method of Van Handel (34). Glucose content in the incubation medium was measured before and after incubation by the method of Washko and Rice (36). Lactate content in the medium was determined by the method of Hohorst (1.3). Tissue DNA was determined by the method of Schneider (18).

Lipid analysis was performed after the slices were removed from the medium, washed in buffer solution, and lyophilized at $-30^{\circ}$. Total lipids were extracted according to the method of Folch et al. (10) under nitrogen, using a Polytron homogenizer (Brinkman Instruments). Phospholipids were separated from neutral lipids by silicic acid column chromatography. The phospholipid fraction was then fractionated into various components by thin layer chromatography on Silica Gel H-coated plates. The plates were developed in chloroform-methanol-water $(65: 25: 4)$. The phosphatidyl choline and phosphatidyl ethanolamine fractions were recovered and quantitated on the basis of phosphorus content determined by the method of Bartlett (2). Radioactivity was measured in a liquid scintillation counter. Molar incorporation of labeled glucose into the various products was determined on the basis of substrate specific activities. Statistical analysis was performed using a paired $t$-test.

\section{RESULTS}

Lung DNA concentrations before incubation in the control and cortisol groups were almost identical, $5.32 \pm 0.94$ (SD) $\mathrm{mg} /$ $\mathrm{g}$ lung in the controls and $5.35 \pm 0.86$ (SD) $\mathrm{mg} / \mathrm{g}$ in the treated group. The wet weight to dry weight ratio was not significantly different between the groups, $9.17 \pm 0.57$ (SD) for the controls and $8.49 \pm 0.69$ (SD) for the cortisol group.

Table 1 demonstrates that glucose consumption calculated from disappearance of glucose from the medium during the 90min incubation significantly increases in the tissues treated with cortisol in vivo, $17.61 \pm 5.56$ (SD) $\mu \mathrm{mol} / \mathrm{g}$ lung as compared to $14.28 \pm 5.78(\mathrm{SD}) \mu \mathrm{mol} / \mathrm{g}$ in the controls $(P<0.05)$. There are no significant differences in glucose oxidation or lactate production between control tissue and tissue treated with cortisol. Before incubation, glycogen content of tissues treated with cortisol is significantly reduced compared with the controls, $2.42 \pm$ $0.97(\mathrm{SD}) \mathrm{mg} / \mathrm{g}$ lung versus $3.81 \pm 1.05(\mathrm{SD}) \mathrm{mg} / \mathrm{g}(P<0.05)$. This reduction persists after incubation.

The content of phosphatidyl choline, phosphatidyl ethanolamine, and neutral lipid in lung slices after 90 min of incubation is shown in Table 2. No significant changes are found after treatment with cortisol. Table 3 demonstrates that treatment

Table 1. Glucose consumption, glucose oxidation, and lactate production expressed as micromoles per g lung (mean $\pm S D$ ); glycogen content expressed as milligrams perg lung (me'an $\pm S D$ )

\begin{tabular}{lrccc}
\hline & $n$ & \multicolumn{1}{c}{ Control } & \multicolumn{1}{c}{ Cortisol } & $P$ value \\
\hline Glucose consumption & 8 & $14.28 \pm 5.78$ & $17.61 \pm 5.56$ & $<0.05$ \\
Glucose oxidation & 9 & $0.272 \pm 0.128$ & $0.283 \pm 0.144$ & NS \\
Lactate production & 10 & $19.21 \pm 6.85$ & $18.43 \pm 10.34$ & NS \\
Glycogen content & & & & \\
$\quad$ Before incubation & 9 & $3.81 \pm 1.05$ & $2.42 \pm 0.97$ & $<0.05$ \\
After incubation & 10 & $3.07 \pm 1.14$ & $2.20 \pm 0.84$ & $<0.01$ \\
\hline
\end{tabular}

Table 2. Content of phosphatidyl choline and phosphatidyl ethanolamine expressed as micromoles per glang (mean $\pm S D)$ ); neutral lipid expressed as milligrams. per glung (mean $\pm S D)$

\begin{tabular}{lrccc}
\hline & $n$ & Control & Cortisol & $\begin{array}{c}P \\
\text { value }\end{array}$ \\
\hline $\begin{array}{l}\text { Phosphatidyl choline } \\
\text { Phosphatidyl ethanol- }\end{array}$ & 10 & $5.89 \pm 1.24$ & $6.22 \pm 0.82$ & NS \\
$\begin{array}{l}\text { amine } \\
\text { Neutral lipid }\end{array}$ & $2.88 \pm 0.43$ & $2.76 \pm 0.62$ & NS \\
\hline
\end{tabular}

Table 3. Incorporation of $/ 6-^{14} \mathrm{C} /$ glucose into various products, expressed as micromoles of glucose per g lung (mean $\pm S D$ )

\begin{tabular}{lrccc} 
& $n$ & Control & Cortisol & $\begin{array}{c}I^{\prime} \\
\text { value }\end{array}$ \\
\hline $\begin{array}{l}\text { Glycogen } \\
\text { Phosphatidyl cho- } \\
\text { line }\end{array}$ & 7 & $0.039 \pm 0.012$ & $0.047 \pm 0.013$ & $<0.01$ \\
$\begin{array}{l}\text { Phosphatidyl eth- } \\
\text { anolamine }\end{array}$ & 7 & $0.023 \pm 0.015$ & $0.027 \pm 0.014$ & NS \\
\begin{tabular}{l} 
Neutral lipid \\
\hline
\end{tabular} & 7 & $0.029 \pm 0.018$ & $0.032 \pm 0.014$ & NS \\
\hline
\end{tabular}

${ }^{1}$ Expressed as micromoles of $\left[6-{ }^{14} \mathrm{C}\right]$ glucose per $\mathrm{mg}$ glycogen.

with cortisol results in significantly enhanced incorporation o the ${ }^{14} \mathrm{C}$ label into phosphatidyl choline $(P<0.01)$. No signifi cant effect is seen in the incorporation of the ${ }^{14} \mathrm{C}$ label ints phosphatidyl ethanolamine or neutral lipid. A significant in crease in incorporation of the ${ }^{14} \mathrm{C}$ label into glycogen occurs afte: treatment with cortisol $(P<0.05)$. In Table 4 the amount o glucose converted into $\mathrm{CO}_{2}$, glycogen, phosphatidyl choline phosphatidyl ethanolamine, and neutral lipid is expressed as : percentage of total glucose consumed. These products accoun for approximately $11 \%$ of glucose consumed. Treatment witl cortisol does not modify the percentage of glucose utilized for the synthesis of $\mathrm{CO}_{2}$, glycogen, phosphatidyl ethanolamine, of neutral lipid. Incorporation of glucose into phosphatidyl cholint is augmented after treatment with cortisol, resulting in a signifi. cant increase over the control, from $1.48 \pm 0.60 \%$ (SD) to 1.7 : $\pm 0.63 \%$ of total glucose consumption $(P<0.01)$.

Table 5 shows the distribution of ${ }^{14} \mathrm{C}$ in the fatty acid anc glycerol moieties of phosphatidyl choline, phosphatidyl ethanol. amine, and neutral lipid expressed as a ratio of fatty acids tc glycerol. Cortisol treatment does not affect these ratios.

\section{DISCUSSION}

The results of this study demonstrate that antepartum cortiso administration is associated with a significant decrease in feta lung glycogen content. Although lung glycogen depletion occur: normally during maturation, administration of cortisol signifi. cantly enhances the rate of depletion. In addition. the rate o incorporation of glucose into glycogen increases after cortiso administration implying increased glycogen turnover. Our find ing of lung glycogen depletion with cortisol treatment is consist ent with morphologic studies showing an accelerated decrease it glycogen content of alveolar type II cells in cortisol treated feta rabbits $(15,24,35)$.

Glucose, a product of glycogenolysis, undergoes a significan increase in consumption after cortisol administration. Cortiso significantly increases the amount of glucose utilized for glyco gen and phosphatidyl choline. Cortisol also increases the amoun of glucose utilized for $\mathrm{CO}_{2,}$, phosphatidyl ethanolamine. an neutral lipid, but not significantly. The percentage of glucos consumed which is utilized for $\mathrm{CO}_{2}$, glycogen, phosphatidy ethanolamine, and neutral lipid is not significantly changed wit cortisol treatment. This percentage is significantly increased fo phosphatidyl choline synthesis only. The increased amount a well as increased percentage of glucose consumed for phosphati dyl choline synthesis indicate that there is preferential incorpori 
tion of glucose into phosphatidyl choline as compared with other lipids after cortisol treatment. These products account for approximately $11^{c^{\prime}}$ ' of glucose consumed. The remaining glucose is probably converted into other cellular components such as proteins, carbohydrates, nucleic acids, and other lipids. We have measured only a small fraction of the compounds involved in zellular metabolism.

Figure 1 demonstrates the metabotic pathways by which glusose may be incorporated into both the glyecrol and fatty acid portions of the phosphatidyl choline molecule $(3,4,9,1+, 30)$. Via the glycolytic pathway, the interconvertible trioses, glyceraldehyde 3-phosphate and dihydroxyacetone phosphate are formed. Glyceraldehyde 3-phosphate continues in the glycolytic pathway to produce pyruvic acid which, when oxidized, results in the formation of acetyl-COA. Acetyl-(o) $\mathrm{A}$ is a precursor for fatty acids, and, bound to coenzyme $A$, fatty acids can enter the pathway for phosphatidyl choline synthesis. At least two pathways may be involved in the utilization of dihydroxyacetone phosphate in forming the glycerol moiety of phosphatidyl choline (21). In the major pathway, dihydroxyacetone phosphate is converted to glycerol 3-phosphate. This may be followed by the addition of two acyl groups, which results in the formation of phosphatidic acid, an important precursor of phosphatidyl choline. Dihydroxyacetone phosphate and glycerol 3-phosphate recently have been shown to be precursors for phosphatidyl choline in microsomal preparations of alveolar type II cells (31). These trioses provide acceptor molecules for fatty acids. If specific products generated during glycolysis are utilized for phospholipid synthesis in fetal lung, then the regulation of glycolysis by gluecerticoids may influence the rate of phosphatidyl chofine production from glycolytic substrates. Glucose metabolism would also generate reduced pyridine nucleotides utilized for the reductive synthetic steps in phosphatidyl choline production.

The total content of phosphatidyl choline in lung tissue wats found not to be appreciably affected by cortisol treatment. This confirms a previous report by Russell e't al. (27), who suggested that a qualitative change with treatment, such as an increased proportion of saturated phosphatidyl choline, may occur in the phosphatidyl choline only at the alveolar surface. It is also possible that glucocorticoids increase secretion of surfactant onto the alveolar surface and also increase surfactant synthesis so that altered rates of lung phosphatidyl choline synthesis are not reflected by parenchymal phosphatidy choline content. When lung phosphatidyl choline is measured after incubation, ats was done in the study by Russell et al. and in the present study. it is probably mostly the parenchymal phosphatidyl choline that is measured if the medium is not analyzed. We hate measured the content of phosphatidyl choline in lung slices from adult rats

Table 4. Incorporation of $/ 0{ }^{11} \mathrm{C} / \mathrm{g} / \mathrm{lucose}$ into barious products, expressed as percentage of total glucose consumption $($ (me'an $\pm S I))$

\begin{tabular}{|c|c|c|c|c|}
\hline --- & $n$ & cintrol & Cortisol & r value \\
\hline Gilycogen & 6 & $4.24 \pm 2.011$ & $+.23 \pm 1.87$ & NS \\
\hline Phosphatidy choline & 4 & $1.48=0.600$ & $1.72 \pm 0.6 .3$ & $=0.01$ \\
\hline $\begin{array}{l}\text { Phosphatidyl ethat } \\
\text { nolamine }\end{array}$ & 4 & $0.92 \pm 0.53$ & $1.08 \pm 0.75$ & $N S$ \\
\hline Neutrall lipid & 3 & $1.20 \pm 0.74$ & $1.32 \pm 0.67$ & $\mathrm{NS}$ \\
\hline Carbon dioxide & 6 & $3.30+1.97$ & $2.77 \pm 1.68$ & $\mathrm{NS}$ \\
\hline
\end{tabular}

Table 5. Incorporation of /6-1' C /glucose into fatty acid and glycerolof various products, expressed as a ratio (me'an $\pm S I)$ ) of

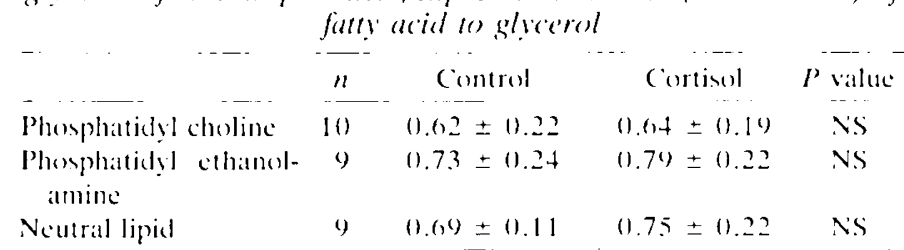

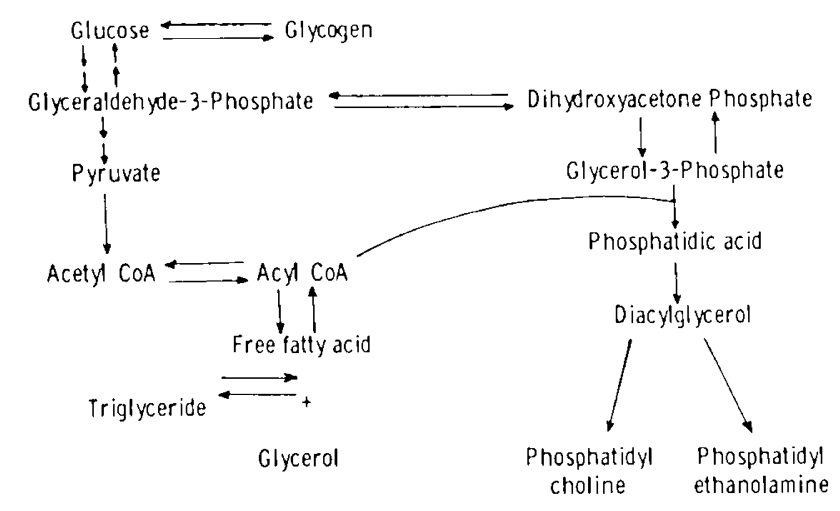

Fig. 1. Scheme hy which glucose can be converted into phosphatidyl choline. Single arrow head indicates onc-step reactions and double arrow heads indicate multiple step reactions.

after 90 min of incubation and in whole lung before incubation and found an average loss of $28 \%$ in saturated phosplatidyl choline content in 30 paired experiments. Thus, the slicing procedure or the incubation is accompanied by appreciable losses in phosphatidyl choline. During the incubation, phosphat tidyl choline could be lost into the medium. Although the lung slice technicue is valid in certitin instances (26), it may not accurately reflect phospholipid secretion onto the alveolair surface. Gilder and MeSherry (11) found that total phospholipid content was not well related to the level of phosphatidyl choline synthesis in lung slices from nomal rabbits.

When lung slices from adult rats are incubated with labeled glucose, over gor\% of the radioactivity recovered in the plaspholipid fraction is found in the glycerol moiety of the molecule (9). We found that only about of $\%$ of the radionctivity is in the glycerol portion. A similar finding was reported by Hamosh (12), who also used fetal rabbits. Possibly more glucose is utilized for fatte acid sinthesis in the fetus than in the adult.

When glucose labeled in the oth catbon atom is used as a tracer, one finds the minimum level of labeled (o). generated. Thus, the oth carbon atom is more likely to be incorporated into phosphatidyl choline. In the pentose cycle, the first carbon atom of glucose is most readily oxidized, whereas in glycolysis carbon atom numbers 3 and t are most readily oxidized. Consepuently, in both glycolysis or in the pentose cycle, the foth carbon atom has the greatest tendency to become incorporated into dihydroxyacetone phosphate. Futhermore, the oth carbon of glucose is most likely to become the methyl carbon of acetyl-cos (18). Calculation of glucose oxidation using $\left[6^{-11} \mathrm{C} \mid\right.$ glucose has limited validity because of the necessary assumption of equal rates of oxidation of all glucose carbon atoms.

Beciuse cortisol induces morphologic changes in the fetal lung. metabolic effects following cortisol treatment might not be direct effects of the glucocorticoids, but rather at conseyuence of the fact that mumerous changes hate occured in the lung. such as maturation of the ape II cells $(15,24,35)$.

\section{CONCITISION}

It can be concluded that cortisol administration to rabbits in vive results in increased glucose consumption by fetal lung tissue slices. This is accompanied by depletion of glycogen and increased incorporation of glucose into phosphatidy choline. Glucose serves as a substrate for phosphatidyl choline synthesis and. in the presence of glucocorticoids, the flux of glucose to phosphatidyl choline is specifically increased. Glycogen appears to be at source of glacose for phosphatidyl choline synthesis.

RIFHREN(TES ANI) NOTIES

1. Barrett, C. T. Sevanian, A., Lavin, N., and Kaplan. S. A.: Role of atemosine $3^{\prime}, 5^{\prime}-$ monophosphate in matturation of fetal lungs. Pediat. Res., $10: 621$ (1)76). 
2. Bartlett, G. R.: Phosphorus assay in column chromatography. J. Biol. (hem., 234: $466(1959)$

3. Bremer, J., and Greenberg. D.Mt: Methyl transfering enzeme system of microsomes in the biosinthesis of lecithin. Biochim. Biophys. Acta, 46. $205,(1961)$.

4. Coleman, R., and Hubscher, G.: Metabolism of phospholipids. Biochim. Biophys. Actit, 56: $479(1962)$.

5. Dawes, G. S.. and Shelly, H. J.: Physiological aspects of carhohydrate metabolism in the foetus and newborn. In: F. Dickens, P. J. Randle, and W. J. Whelan: Carbohydrate Metabolism and its Disorders, Vol. 2, Chap. 4, p. 87 (Academic Press. New York. 1968).

6. De Lemos, R. A., and Mclaughlin, G. W.: Induction of the pulmonary surfactant in the fetal primate by the intratuterine administration of corticosteroids. Amer. Rev. Resp. Dis.. 102: 450 (1970).

7. Farrell, P. M.: Regulation of pulmonary lecithin synthesis, In: C.A. Villec, D). B. Villee, and J. Zuckerman: Respiratory Distress Syndrome, p. 311 , (Academic Press, New York, 1973).

8. Farrell, P. M., and Zachman, R. D.: Induction of choline phosphotransferase and lecithin synthesis in the fetal lung by corticosteroids. Science, 197: 297 (1973).

9. Felts. J. M.: Biochemistry of the lung. Health Phys., 10: 973 (196.t)

10. Folch, J., lees, M. and Sloane-Stanley, G. M: A simple method for the isolation and purification of total lipids from annimal tissues. J. Biol. Chem. 226: $497(1957)$

11. Gilder, H. and McSherry, C.: An improved method for measuring the incorporation of palmitic acid into lung lecithin. Amer. Rev. Resp. Dis.. 106 : $556(1972)$.

12. Hamosh, M. Schechter, Y. and Hamosh, P.: Personal communication.

13. Hohorst, H. J.: L-(+)-lactate determination with lactic dehydrogenase and DNP. In: H. U. Bergmeyer: Methods of Enzymatic Analysis, p. 226-270 (Academic Press, New York, 1965).

14. Kennedy. E. P.: Metabolism of lippides. Ann. Rev. Biochem.. 26: 119 (1957)

15. Kikkatwa, Y., Kiabara, M. Motoyama, E. K., Orzaleski, M. M. and Cook, (C D .: Morphologic development of fetal rabhit lung and its acceleration with cortisol. Amer. J. Pathol. 64: 423 (1971).

16. Klaus, M. H., Reiss, O. K., Tooley, W. H.. Piel, C. and Clements, J. A.: Alveolar epithelial cell mitechomiria as a source of the surface-active lung lining. Science, 1.37: 750 (1962).

17. Kotas, R. V. and Avery, M. E.: Accelerated appearance of pulmonary surfactant in the fetal rabbit. J. Appl. Physiol., 30: 358 (1971).

18. Landau, B. R. and Kitz, J.: Pathways of glucose metabolism. In: A. F Renold and G. F. Cahill. Jr.: Handbook of Physiologe. Sect. 5. p. 253 (American Physiological Society. Washington. D).C. 1965)

19. Liggins. G. C.: Premature delivery of fetal lambs infused with glucocorticoids. J. Endocrinol.. 45: $515(1969)$.

20. Liggins, G. C. and Howic, R.: A controlled trial of antepartum glucocorticoid treatment for the prevention of respiratory distress syndrome in premature infants. Pediatrics 5()$: 515(1972)$.

21. Masoro, E. J.: Development of the ensyme of lipid hiosynthesis in the human fetus. In: C. A. Villece, D. B. Villee, and J. Zuckerman: Respiratory Distress Syndrome, p. 7 (Academic Press, New York, 1973).

22. Mims, L. C. and Kotas, R. J.: (ilycerol as a phosphatidel choline precursor in the developing mamalian lung. Biol. Neonate, 22: 4.36 (197.3)
23. Mokrasch, L. C., Davidson, W. D. and McGilvery, R. W.: The response to gluconeogenic stress of fructose-1,6-diphosphatase in rabbit liver. J. Biol. Chem.. 222: 179 (1956)

24. Motoyama. 1. K.. Orzaleski. M. M. Kikkawa. Y.. Kiabara. M.. Wu. B.. Zigas. C. J.. and Cook. ('. D).: Ifffect of cortisol on the maturation of fetal rabbit lungs. Pediatrics, 48: 5.47 (1971)

25. Mukherjec. S. P. and Mukherjec. C.: Control of rat adipose tissue metabolism by cortisone in relation to epinephrinc. Amer. J. Physiol..224: $898(1973)$

26. () Neil. J. J. and Tierney. D). F.: Rat lung metabolism: (ilucose utilization by isclated perfused lungs and tissue sliees. Amer. I. Physiol.. 220: 867 (1974).

27. Russell. B. J.. Nugent. L. and Chernick. V.: Effects of steroids on the enzymatic pathways of lecithin production in fetal rabbits. Biol. Neonate. 24: $306(1974)$

28. Schncider. W'. (C.: Phosphorus compounds in animal tissues. I. Extraction and estimation of desoxypentose nucleic acid and of pentose nucleic acid. J. Biol. (hem.. 101: 293 (1945)

29. Shrago, E.. Lardy. H. A.. Nordlic. R. (C. and Fonter. D. (). Metabolic and hormonal control of phosphocnolpyruvate carboxykinase and malic enzome in rat liver. J. Biol. Chem.. 23.8: $3188(196.3)$

30. Shulzz, F. M. Kiminez. J. M. MatcDonald, P. D. and Johnston, J. M1.: Fetal lung maturation: Phosphatidic acid phosphohydrolase in rabbit lung. Gynccol. Invest.. 5: $222(197.4)$

31. Snyder. F. and Malone. B.: Acyltransferases and the biosinthesis of pulmot nary surfactant lipid in adenoma alveolar type II cells. Biomed. Biophys. Res. Commun. 66: 914 (1975)

32. Themas. Jr.. T. and Rhoades, R. A.: Incorporation of palmitate-1-4e inte lung tissue and "alveolar" lecithin Amer J. Physiol 210. 1535 (1070).

33. Tombropoulos. I: G.: Palmitate incorporation into lipids by lungs subellular fractions. Arch. Biochem. Biophys.. 158: 911 (1973).

34. Van Handel. Fa: Famation of glycogen in small amounts of tissue. Anal. ('hem.. ll: $256(196,5)$

35. Wang. N. S.. Kotas. R. V.. Avery. M. E. and Thurbeck. W. M.: Accelerated appearance of osmiophilic bodies in fetal lungs following steroid injection. J. Appl. Physiol.. 30: 362 (1971).

36. Washko. M. F. and Rice. F. W'.: Determination of glucose by an improved enzymatic procedure. Clin. (hem., 7: 542. (1961).

37. Wether. G.. Allard, C.. Delamirande. G. and Cantero. A.: Increased liver glucose-6-phosphatise activity after cortisone administration. Biochem. Biophys. Actit. 16: 618 (1955).

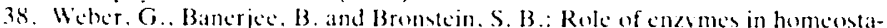
sis III. Selective induction of increase of liver enzymes involved in carbohydrate metabolism. J. Biol. (hem.. 2.36: 3166 (1961).

39. This rescarch was reported in part hefore the Sociely for Pediatric Research. St. I.ouis. Mo.. 1976

40. This rescarch was supported by United States Public Health Service (jrant 4 44.4954-3277!) 3 .

41. Reguests for reprints should he addressed to: (C. T. Barrett. M1.1). Departments of Pediatrics and Medicine. UCLA Scheol of Medicine. Los Angeles. (illif. e(n)24 (USA)

42. Received for publication September 14. 1976.

43. Accepted for publication Decomber 1.1976.

Coprright 1 1977 International Pediatric Research Foundation. Inc. 